\title{
Undertreatment of osteoporosis in the oldest old? A nationwide study of over 700,000 older people
}

\author{
Kristina Johnell • Johan Fastbom
}

Received: 2 December 2008 / Accepted: 11 February 2009 /Published online: 19 March 2009

(C) The Author(s) 2009. This article is published with open access at Springerlink.com

\begin{abstract}
Summary We analysed data from elderly people registered in the Swedish Prescribed Drug Register to investigate whether age is associated with use of osteoporosis drugs in a nationwide population. Our results indicate an undertreatment of osteoporosis, particularly with bisphosphonates, in the oldest old in Sweden.

Introduction The aim of this study was to investigate whether age is associated with use of osteoporosis drugs in a large population of older people.

Methods We analysed data on age, sex, type of residential area (urban/rural) and dispensed drugs for people aged $\geq 75$ years registered in the Swedish Prescribed Drug Register from October to December $2005(n=731,105)$. Multivariate logistic regression was used to analyse whether age was associated with use of osteoporosis drugs, after adjustment for type of residential area and number of other drugs (a proxy for comorbidity).

Results Osteoporosis drugs were used by $16.1 \%$ of the women and $3.4 \%$ of the men. The probability of use of bisphosphonates declined with increasing age [ORwomen= 0.36 (95\% CI $0.34-0.38)$ and ORmen $=0.46$ (95\% CI $0.37-$ 0.56 ) for age $\geq 90$ years vs. $75-79$ years]. Raloxifene was also negatively associated with age. Calcium + vitamin D supplements, however, showed a divergent pattern regarding age. In women, the lowest likelihood of use of calcium + vitamin D supplements occurred in the oldest old ( $\geq 90$ years).

Conclusions Our results indicate an undertreatment of osteoporosis, particularly with bisphosphonates, in the
\end{abstract}

K. Johnell $(\bowtie) \cdot$ J. Fastbom

Aging Research Center, Karolinska Institutet,

Gävlegatan 16,

11330 Stockholm, Sweden

e-mail: Kristina.Johnell@ki.se oldest old in Sweden. Future research is needed for understanding the mechanisms behind this age effect.

Keywords Bisphosphonates $\cdot$ Calcium + vitamin D supplements · Drug register · Elderly · Raloxifene · Register-based research

\section{Introduction}

Osteoporotic fractures are a fundamental cause of morbidity and mortality [1, 2]. Hence, osteoporosis is a major public health problem and imposes a substantial financial burden to the society $[1,3-5]$. The prevalence and costs associated with osteoporosis is expected to increase even further due to the ageing of the population $[6,7]$.

Advanced age is an important and independent risk factor for osteoporosis and fractures [8]. Fracture risk is much higher in the elderly than in the young, even given the same bone mineral density (BMD) [8-11]. In Sweden, regarded as a high-risk country for osteoporosis [8, 12], about $47 \%$ of females and $17 \%$ of males aged $80-84$ years have osteoporosis [13], the mean age of hip fracture is 80 years for women and 76 years for men [14] and the average 10 -year probability of an osteoporotic fracture is about $27 \%$ for women and $13 \%$ for men aged 85 years [11].

Therefore, one would expect that use of osteoporosis drugs increases with increasing age. However, there are indications that the oldest old may be undertreated for osteoporosis [15-18]. Studies have shown that it is particularly cost-effective to treat osteoporosis at higher ages [19], and people with advanced ages are wellrepresented in randomised clinical trials (RCTs) of pharmacological treatment of osteoporosis compared to other geriatric disorders. Thus, there is sufficient documentation 
from RCTs supporting use of bisphosphonates, calcium + vitamin D and raloxifene in people aged 75 years and older, as concluded by The Swedish Council on Technology Assessment in Health Care [20, 21].

The aim of this study was to investigate whether age is associated with use of osteoporosis drugs (i.e., bisphosphonates, calcium + vitamin D supplements and raloxifene) in a large population of older people.

\section{Materials and methods}

\section{Study population}

The individual-based Swedish Prescribed Drug Register (SPDR) was introduced in July 2005 and contains data with unique personal identification numbers for all dispensed prescriptions to the whole population of Sweden (about nine million inhabitants). The data collection is administered by the state-owned National Corporation of Swedish Pharmacies and then transferred to the Centre for Epidemiology at the National Board of Health and Welfare, which is responsible for keeping the register [22]. The SPDR is intended for epidemiological studies, research and statistics within the health care area. Missing data due to personal identification number is about $0.3 \%$ [23].

We analysed non-identifiable data from individuals aged $\geq 75$ years who were registered in the SPDR from October to December 2005, with information about every individual's age, sex, type of residential area (urban/rural) and dispensed drugs (amount of prescribed drug, when the prescription was filled, and prescribed dosage (i.e., from the prescriptions written by the prescribers)). After exclusion of the $0.2 \%(1,125 / 732,230)$ individuals with missing data on place of residence, the study population consisted of 731,105 older people (450,482 women and 280,623 men).

Information from the 3-month period about when the prescription was filled, the amount of drug and the prescribed dosage was processed to calculate the duration of drug exposure $[24,25]$. When the prescribed dosage was incomplete or missing, we used defined daily doses (DDDs) [26] to calculate the duration of drug exposure. The DDD is the assumed average dose per day for a drug used for its main indication in adults [26]. We assumed 0.9 DDDs for regularly used drugs (based on calculations for regularly used drugs among the elderly in the study population) and 0.45 DDDs (50\% of 0.9$)$ for drugs prescribed as needed, as indicated on the prescription. In addition, we assumed one DDD for dermatological and eye preparations.

A list of current prescriptions was constructed based on the calculations of the duration of drug exposures for every individual on the arbitrarily chosen date of 31 December
2005. If a patient was dispensed the same drug in different doses during the study period, this was counted as one dispensed drug.

This study was approved by the ethical board in Stockholm (Dnr 2006/948-31).

\section{Definitions}

Osteoporosis drugs were classified according to their Anatomical Therapeutic Chemical code [26] (M05BA and M05BB for bisphosphonates (etidronic acid, clodronic acid, pamidronic acid, alendronic acid, ibandronic acid, risedronic acid and zoledronic acid), A12AX for the combination of calcium + vitamin D and G03XC01 for raloxifene). Patients on several osteoporosis drugs were categorised as users of all separate drugs. Calcitonin was used by only 20 people, and, therefore, excluded from this study. We also excluded hormone replacement therapy (HRT) because these drugs were in 2005 mainly used for treatment of climacteric symptoms.

Age was categorised into four groups: 75-79 (reference), $80-84,85-89$ and $\geq 90$ years. Number of other drugs, used as a proxy for comorbidity [27, 28], consisted of the number of prescriptions filled by the person other than the osteoporosis drugs under study (i.e., bisphosphonates, calcium + vitamin $\mathrm{D}$ supplements and raloxifene). This variable was divided into four categories: $0-4$ (reference), $5-9,10-14$ and $\geq 15$ drugs.

Type of residential area was classified according to a Statistics Sweden scale into six categories of so called homogeneity regions $(\mathrm{H} 1-\mathrm{H} 6)$ depending on the population density and the number of inhabitants in the nearest vicinity of the main city in that municipality [29].

According to this official homogeneity region classification, the two highest density categories $(\mathrm{H} 1, \mathrm{H} 2)$ include only the largest cities in Sweden: Stockholm, Göteborg and Malmö/Lund. H3 consists of municipalities with more than 90,000 inhabitants within a $30 \mathrm{~km}$ radius from the centre of that municipality. $\mathrm{H} 4$ includes municipalities with more than 27,000 but less than 90,000 inhabitants from the centre of that municipality and also more than 300,000 inhabitants within a $100 \mathrm{~km}$ radius from the same centre. H5 is identical to $\mathrm{H} 4$ except that there are less than 300,000 inhabitants from the centre of the municipality. Finally, H6 consists of municipalities with less than 27,000 inhabitants within a radius of $30 \mathrm{~km}$ from the municipality centre. H4 $\mathrm{H} 6$ were classified as rural (reference) and $\mathrm{H} 1-\mathrm{H} 3$ as urban areas [30].

Statistical analysis

Men and women were analysed separately. Multivariate logistic regression was used to analyse whether age was 
associated with filled prescription of osteoporosis drugs, after adjustment for type of residential area and number of other drugs. The results are shown as odds ratios (ORs) with $95 \%$ confidence intervals (CIs). SPSS 14.0 for Windows (SPSS, 1989-2005) was used for the analyses.

\section{Results}

Mean age among the 731,105 elderly was 82.5 years in women and 81.4 years in men (Table 1). Osteoporosis drugs were used by $16.1 \%$ of the women (bisphosphonates, $5.4 \%$; calcium + vitamin D supplements, $14.2 \%$ and raloxifene, $0.3 \%$ ) and $3.4 \%$ of the men (bisphosphonates, $0.9 \%$ and calcium + vitamin D supplements, 3.1\%). The users of bisphosphonates and raloxifene were younger than the non-users of osteoporosis drugs, whereas the male users of calcium + vitamin D supplements were older (Table 1). Figures 1, 2 and 3 show that the prevalence of the three types of osteoporosis drugs was lowest in the oldest old ( $\geq 90$ years), except for calcium + vitamin D supplements among men. The prevalence of bisphosphonates decreased after 80-84 years, particularly in women (Fig. 1). The use of calcium + vitamin D supplements was most common in the age group 85-89 years (Fig. 2), whereas the prevalence of raloxifene decreased with increasing age throughout the age span (Fig. 3).

Furthermore, users of osteoporosis drugs had on average more non-osteoporosis drugs than the non-users (Table 1). Also, users of osteoporosis drugs lived in urban areas to a greater extent than the non-users.

The multivariate logistic regression analyses (Table 2) showed that the probability of use of bisphosphonates declined with increasing age [ORwomen $=0.36(95 \% \mathrm{CI}$ $0.34-0.38)$ and ORmen $=0.46$ (95\% CI $0.37-0.56)$ for age $\geq 90$ years compared with $75-79$ years], after adjustment for type of residential area and number of other drugs. Raloxifene was also negatively associated with age [ORwomen $=0.24(95 \%$ CI $0.18-0.32)$ for age $\geq 90$ years compared with 75-79 years]. Calcium + vitamin D supplements, however, showed a divergent pattern. In men, these drugs showed an increased probability of use with age, although there was a slight decrease in those aged $\geq 90$ years compared with 85-89 years. In women, the lowest likelihood of use of calcium + vitamin D supplements occurred in the oldest old $\left[\mathrm{OR}_{\mathrm{women}}=0.81(95 \%\right.$ CI 0.78 0.83 ) for age $\geq 90$ years compared with 75-79 years]. Use of osteoporosis drugs, particularly raloxifene, was associated with living in an urban area (Table 2). Moreover, use of other drugs was strongly associated with osteoporosis drug use, particularly in men.

\section{Discussion}

\section{Main findings}

In our nationwide population of older people, about $16 \%$ of the women and $3 \%$ of the men used any osteoporosis drug, which is low compared with the estimated osteoporosis occurrence in Sweden [13]. Thus, it seems like osteoporosis is undertreated in elderly Swedes and particularly in the oldest old ( $\geq 90$ years). These findings are in concordance with results from previous studies regarding age and treatment with osteoporosis drugs $[15,28,31,32]$. One reason for this finding may include physicians' wish to minimise polyphar-

Table 1 Characteristics of the study population according to use of osteoporosis drugs, 2005

\begin{tabular}{|c|c|c|c|c|c|}
\hline & $\begin{array}{l}\text { Study } \\
\text { population }\end{array}$ & $\begin{array}{l}\text { Non-users of } \\
\text { osteoporosis drugs }\end{array}$ & $\begin{array}{l}\text { Users of } \\
\text { bisphosphonates }\end{array}$ & $\begin{array}{l}\text { Users of calcium }+ \\
\text { vitamin D }\end{array}$ & $\begin{array}{l}\text { Users of } \\
\text { raloxifene }\end{array}$ \\
\hline \multicolumn{6}{|l|}{ Women } \\
\hline$n$ & 450,482 & 377,748 & 24,439 & 63,831 & 1,255 \\
\hline Mean age (years $\pm \mathrm{SD})$ & $82.5 \pm 5.4$ & $82.6 \pm 5.5$ & $81.5 \pm 4.6$ & $82.6 \pm 5.2$ & $80.7 \pm 4.4$ \\
\hline \multicolumn{6}{|l|}{ Type of residential area $(n(\%))$} \\
\hline Urban & $299,171(66.4)$ & $247,293(65.5)$ & $17,307(70.8)$ & $45,713(71.6)$ & $1,003(79.9)$ \\
\hline Rural & $151,311(33.6)$ & $130,455(34.5)$ & $7,132(29.2)$ & $18,118(28.4)$ & $252(20.1)$ \\
\hline Mean number of other drugs (no. \pm SD) & $5.4 \pm 3.9$ & $5.2 \pm 3.8$ & $6.3 \pm 4.4$ & $6.5 \pm 4.3$ & $5.8 \pm 4.2$ \\
\hline \multicolumn{6}{|l|}{ Men } \\
\hline$n(\%)$ & 280,623 & 270,965 & 2,478 & 8,799 & - \\
\hline Mean age (years $\pm \mathrm{SD}$ ) & $81.4 \pm 4.9$ & $81.4 \pm 4.9$ & $80.9 \pm 4.3$ & $82.0 \pm 4.8$ & \\
\hline \multicolumn{6}{|l|}{ Type of residential area $(n(\%))$} \\
\hline Urban & $180,921(64.5)$ & $174,197(64.3)$ & $1,685(68.0)$ & $6,177(70.2)$ & \\
\hline Rural & $99,702(35.5)$ & $96,768(35.7)$ & $793(32.0)$ & $2,622(29.8)$ & \\
\hline Mean number of other drugs (no. $\pm \mathrm{SD}$ ) & $5.1 \pm 3.7$ & $5.0 \pm 3.7$ & $7.1 \pm 4.4$ & $7.1 \pm 4.3$ & \\
\hline
\end{tabular}




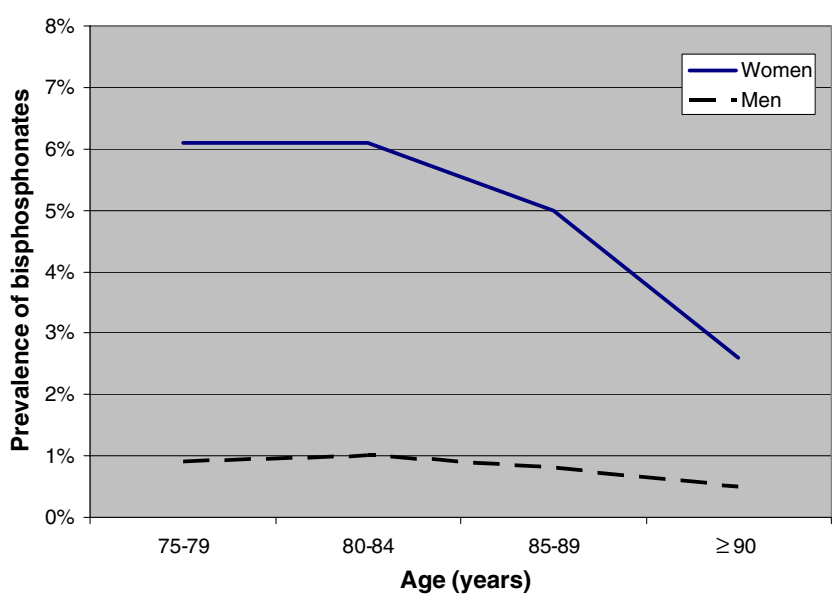

Fig. 1 Prevalence of bisphosphonates according to age $(450,482$ women and 280,623 men)

macy in the frail oldest old [32]. However, use of many drugs was strongly associated with use of osteoporosis drugs [28, 32], so this explanation seems less probable. Other explanations might be physicians' and elderly patients' attitudes and knowledge of osteoporosis and osteoporosis drugs, older patient's lack of communication skills (maybe due to cognitive impairment) and non-adherence in the oldest old [33].

The prevalence of bisphosphonates was generally low ( $5 \%$ for women and $1 \%$ for men) and higher age, particularly in women, was associated with decreased use of bisphosphonates. Treatment with bisphosphonates is well-documented in the elderly and these drugs have an overall favourable safety profile $[6,8,34]$. The costeffectiveness of bisphosphonates in the elderly has also been established [8, 35-37]. Thus, there seem to be opportunities for improvement in treatment with bisphosphonates in older Swedes. Nevertheless, the Hip Intervention Program Study Group concludes that the bisphosphonate risedronate reduces the risk of hip fracture in elderly

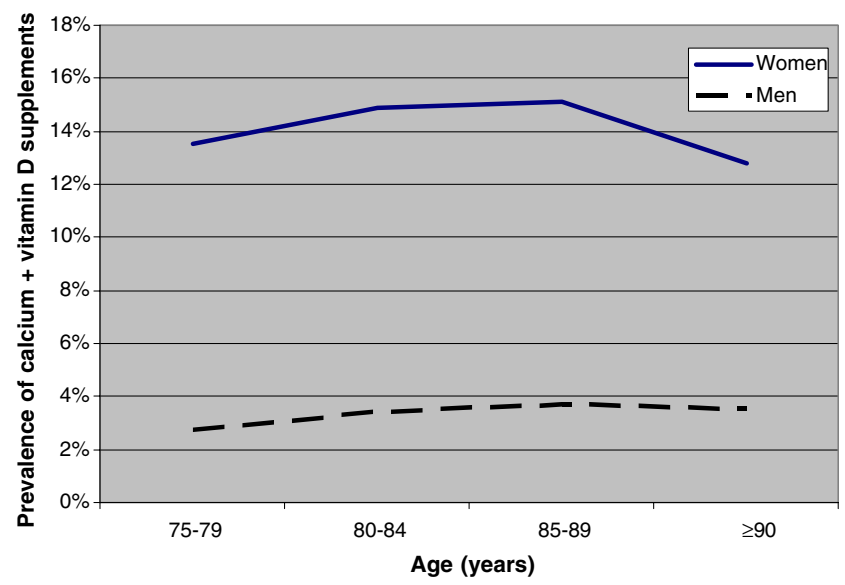

Fig. 2 Prevalence of calcium + vitamin D supplements according to age (450,482 women and 280,623 men)

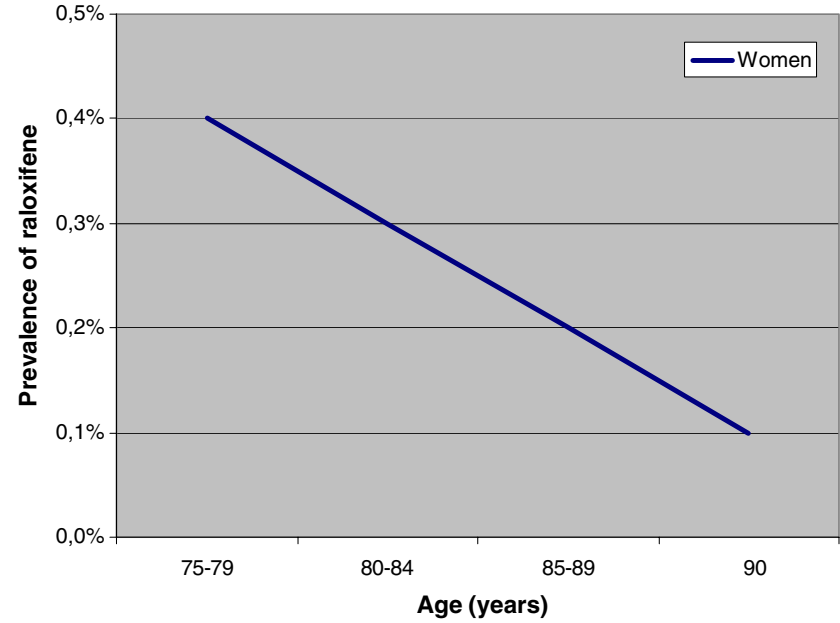

Fig. 3 Prevalence of raloxifene according to age (450,482 women)

women with confirmed osteoporosis but not in elderly women selected primarily on the basis of risk factors other than low BMD [38]. The selective oestrogen receptor modulator raloxifene is a newer type of osteoporosis drug, and, hence, not as well-studied as the bisphosphonates. Raloxifene is mainly regarded as suitable for postmenopausal women, who would previously been prescribed HRT $[15,34]$, which would explain the decreased use in the older participants in our study.

The most common type of osteoporosis drug was calcium + vitamin D supplements, which is in concordance with previous research [31]. Calcium + vitamin D supplements are regarded as less potent than bisphosphonates and raloxifene, and are most likely only effective in deficient patients $[8,34]$. In women, the prevalence and likelihood of use of calcium + vitamin D supplements were lowest in the oldest old, even though frail older women confined to institutions sustain fewer fractures if given calcium + vitamin D supplements [39]. To our knowledge, there are no evidence-based guidelines supporting a reduced use in the oldest old women.

In concordance with previous studies [17, 31, 32, 40, 41], it seems as if men are particularly undertreated for osteoporosis, although mortality for most osteoporotic fractures has been reported to be higher in men than in women [42]. Nevertheless, osteoporosis in men has only recently been broadly recognised [43] and the treatment rates may be expected to increase as the awareness of male osteoporosis improves. Moreover, the stronger association observed in our study between use of other drugs and use of osteoporosis drugs in men, indicates that males treated for osteoporosis may have more comorbid conditions than their female counterparts. Thus, men seem to be in a worse condition than women when treated for osteoporosis.

Furthermore, living in an urban area was associated with a higher probability of osteoporosis treatment. Explanations 
Table 2 Adjusted odds ratios (ORs) with 95\% confidence intervals (95\% CIs) for dispensed osteoporosis drugs in 450,482 women and 280,623 men in Sweden, 2005

Bisphosphonates OR $(95 \% \mathrm{CI}) \quad$ Calcium + vitamin D supplements OR

Raloxifene OR

(95\% CI) (95\% CI)

\begin{tabular}{|c|c|c|c|}
\hline \multicolumn{4}{|l|}{ Women } \\
\hline \multicolumn{4}{|c|}{ Age (years) } \\
\hline $75-79$ & Ref & Ref & Ref \\
\hline $80-84$ & $0.95(0.93,0.98)$ & $1.06(1.04,1.08)$ & $0.76(0.67,0.86)$ \\
\hline $85-89$ & $0.75(0.72,0.77)$ & $1.02(1.00,1.05)$ & $0.48(0.40,0.56)$ \\
\hline$\geq 90$ & $0.36(0.34,0.38)$ & $0.81(0.78,0.83)$ & $0.24(0.18,0.32)$ \\
\hline \multicolumn{4}{|c|}{ Type of residential area } \\
\hline Rural & Ref & Ref & Ref \\
\hline Urban & $1.25(1.21,1.29)$ & $1.34(1.31,1.36)$ & $2.03(1.76,2.33)$ \\
\hline \multicolumn{4}{|c|}{ Number of other drugs } \\
\hline $0-4$ & Ref & Ref & Ref \\
\hline $5-9$ & $1.40(1.36,1.44)$ & $1.60(1.57,1.63)$ & $1.12(0.99,1.27)$ \\
\hline $10-14$ & $1.94(1.86,2.01)$ & $2.19(2.13,2.25)$ & $1.56(1.32,1.85)$ \\
\hline$\geq 15$ & $2.63(2.47,2.80)$ & $2.77(2.66,2.89)$ & $1.70(1.26,2.28)$ \\
\hline \multicolumn{4}{|l|}{ Men } \\
\hline \multicolumn{4}{|c|}{ Age (years) } \\
\hline $75-79$ & Ref & Ref & - \\
\hline $80-84$ & $1.00(0.92,1.10)$ & $1.19(1.13,1.25)$ & \\
\hline $85-89$ & $0.79(0.71,0.89)$ & $1.25(1.18,1.33)$ & \\
\hline$\geq 90$ & $0.46(0.37,0.56)$ & $1.10(1.01,1.20)$ & \\
\hline \multicolumn{4}{|c|}{ Type of residential area } \\
\hline Rural & Ref & Ref & \\
\hline Urban & $1.16(1.07,1.26)$ & $1.30(1.24,1.36)$ & \\
\hline \multicolumn{4}{|c|}{ Number of other drugs } \\
\hline $0-4$ & Ref & Ref & \\
\hline $5-9$ & $2.05(1.86,2.25)$ & $2.15(2.04,2.26)$ & \\
\hline $10-14$ & $3.36(2.99,3.78)$ & $3.40(3.19,3.62)$ & \\
\hline$\geq 15$ & $5.61(4.74,6.64)$ & $5.07(4.61,5.58)$ & \\
\hline
\end{tabular}

for this finding may be a higher rate of osteoporosis and fractures in urban areas [44-47] longer distance to BMD testing in rural areas [28] and availability of specialist care.

\section{Limitations}

The cross-sectional design of our study does not allow us to draw conclusions regarding causality. The SPDR does not include information about the underlying indications and diagnoses for prescription of drugs. We also lacked information about comorbidity. However, we did control for a proxy for overall comorbidity (i.e., number of other drugs) [27, 28].

We analysed data on elderly patients registered in the SPDR from October to December 2005, which corresponded to $91 \%$ of the population aged 75 years and older in Sweden (according to Statistics Sweden's census data from 31 December 2005). The SPDR does not include data on over-the-counter drugs, which only concerns calcium + vitamin D supplements in this study. Calcium + vitamin D supplements can be purchased both with and without a prescription in Sweden. However, we were specifically interested in prescribing practise regarding osteoporosis drugs. Therefore, the lack of information about use of nonprescription drugs was not a substantial problem in this particular study. Also, the register does not include drugs used in hospitals or from drug storerooms sometimes used in nursing homes, which may lead to an underestimation of older people's drug use. Moreover, our method is built on an assumption that all current drugs were dispensed during the observed 3-month period, which is based on the fact that drugs are prescribed for use during at most 90 days in Sweden. Therefore, we might have missed drugs that were dispensed before the 3-month period and used at a slower rate than intended. At the same time, we might have included drugs that were dispensed during the 3-month 
period but discontinued prematurely. In addition, our method is based on interpretations of the dispensed drugs' dosages written by the prescribers, as well as assumptions about DDDs when information about dosage was incomplete or missing (about $15 \%$ of the regularly used drugs) $[24,25]$.

Finally, a general limitation of studies on drug registers is that data on dispensed drugs are not synonymous with neither prescribed nor used drugs. Some prescriptions may never be filled at pharmacies and adherence to treatment can be low [33].

\section{Conclusions}

Our results indicate an undertreatment of osteoporosis, particularly with bisphosphonates, in the oldest old in Sweden. Future research in other large study populations is needed for understanding the mechanisms behind this age effect.

Acknowledgements We thank the Centre for Epidemiology at the National Board of Health and Welfare for providing data. This study was supported financially by grants from the Swedish Council for Working Life and Social Research and the Swedish Research Council.

Conflicts of interest None.

Open Access This article is distributed under the terms of the Creative Commons Attribution Noncommercial License which permits any noncommercial use, distribution, and reproduction in any medium, provided the original author(s) and source are credited.

\section{References}

1. Johnell O, Kanis JA (2006) An estimate of the worldwide prevalence and disability associated with osteoporotic fractures. Osteoporos Int 17:1726-1733

2. Johnell O, Kanis JA, Oden A, Sernbo I, Redlund-Johnell I, Petterson C, De Laet C, Jonsson B (2004) Mortality after osteoporotic fractures. Osteoporos Int 15:38-42

3. Perreault S, Dragomir A, Blais L, Moride Y, Rossignol M, SteMarie LG, Fernandes JC (2008) Population-based study of the effectiveness of bone-specific drugs in reducing the risk of osteoporotic fracture. Pharmacoepidemiol Drug Saf 17:248-259

4. Johnell O, Kanis JA, Jonsson B, Oden A, Johansson H, De Laet C (2005) The burden of hospitalised fractures in Sweden. Osteoporos Int 16:222-228

5. Borgstrom F, Zethraeus N, Johnell O, Lidgren L, Ponzer S, Svensson O, Abdon P, Ornstein E, Lunsjo K, Thorngren KG, Sernbo I, Rehnberg C, Jonsson B (2006) Costs and quality of life associated with osteoporosis-related fractures in Sweden. Osteoporos Int 17:637-650

6. Ettinger MP (2003) Aging bone and osteoporosis: strategies for preventing fractures in the elderly. Arch Intern Med 163:2237-2246

7. Goettsch WG, de Jong RB, Kramarz P, Herings RM (2007) Developments of the incidence of osteoporosis in The Netherlands: a PHARMO study. Pharmacoepidemiol Drug Saf 16:166-172
8. Kanis JA, Burlet N, Cooper C, Delmas PD, Reginster JY, Borgstrom F, Rizzoli R (2008) European guidance for the diagnosis and management of osteoporosis in postmenopausal women. Osteoporos Int 19:399-428

9. Gajic-Veljanoski O, Sebaldt RJ, Davis AM, Tritchler D, Tomlinson G, Petrie A, Adachi JD, Cheung AM (2007) Age and drug therapy are key prognostic factors for first clinical fracture in patients with primary osteoporosis. Osteoporos Int 18:1091-1100

10. Siris ES, Brenneman SK, Barrett-Connor E, Miller PD, Sajjan S, Berger ML, Chen YT (2006) The effect of age and bone mineral density on the absolute, excess, and relative risk of fracture in postmenopausal women aged 50-99: results from the National Osteoporosis Risk Assessment (NORA). Osteoporos Int 17:565-574

11. Kanis JA, Johnell O, Oden A, Dawson A, De Laet C, Jonsson B (2001) Ten year probabilities of osteoporotic fractures according to BMD and diagnostic thresholds. Osteoporos Int 12:989-995

12. Kanis JA, Johnell O, De Laet C, Jonsson B, Oden A, Ogelsby AK (2002) International variations in hip fracture probabilities: implications for risk assessment. J Bone Miner Res 17:1237-1244

13. Kanis JA, Johnell O, Oden A, Jonsson B, De Laet C, Dawson A (2000) Risk of hip fracture according to the World Health Organization criteria for osteopenia and osteoporosis. Bone 27:585-590

14. Johnell O, Kanis J (2005) Epidemiology of osteoporotic fractures. Osteoporos Int 16(Suppl 2):S3-7

15. Huot L, Couris CM, Tainturier V, Jaglal S, Colin C, Schott AM (2008) Trends in HRT and anti-osteoporosis medication prescribing in a European population after the WHI study. Osteoporos Int 19:1047-1054

16. Feldstein A, Elmer PJ, Orwoll E, Herson M, Hillier T (2003) Bone mineral density measurement and treatment for osteoporosis in older individuals with fractures: a gap in evidence-based practice guideline implementation. Arch Intern Med 163:2165-2172

17. Port L, Center J, Briffa NK, Nguyen T, Cumming R, Eisman J (2003) Osteoporotic fracture: missed opportunity for intervention. Osteoporos Int 14:780-784

18. Freedman KB, Kaplan FS, Bilker WB, Strom BL, Lowe RA (2000) Treatment of osteoporosis: are physicians missing an opportunity? J Bone Joint Surg Am 82-A:1063-1070

19. Strom O, Borgstrom F, Sen SS, Boonen S, Haentjens P, Johnell O, Kanis JA (2007) Cost-effectiveness of alendronate in the treatment of postmenopausal women in 9 European countriesan economic evaluation based on the fracture intervention trial. Osteoporos Int 18:1047-1061

20. SBU-The Swedish Council on Technology Assessment in Health Care. Osteoporosis - prevention, diagnosis and treatment. A systematic review. 2003.

21. SBU-The Swedish Council on Technology Assessment in Health Care. Geriatric care and treatment. A systematic compilation of existing scientific literature. 2003.

22. Wettermark B, Hammar N, Fored CM, Leimanis A, Otterblad Olausson P, Bergman U, Persson I, Sundstrom A, Westerholm B, Rosen M (2007) The new Swedish Prescribed Drug Registeropportunities for pharmacoepidemiological research and experience from the first six months. Pharmacoepidemiol Drug Saf 16:726-735

23. The Swedish National Board of Health and Welfare. Register on prescribed pharmaceuticals in Sweden. http://www.socialstyrelsen. se/en/about/epc/Register+on+prescribed+pharmaceuticals + in + Sweden.htm

24. Lau HS, de Boer A, Beuning KS, Porsius A (1997) Validation of pharmacy records in drug exposure assessment. J Clin Epidemiol 50:619-625

25. Johnell K, Fastbom J, Rosen M, Leimanis A (2007) Inappropriate drug use in the elderly: a nationwide register-based study. Ann Pharmacother 41:1243-1248 
26. WHO Collaborating Centre for Drug Statistics Methodology, Oslo, Norway. About the ATC/DDD system.http://www.whocc. no/atcddd/

27. Schneeweiss S, Seeger JD, Maclure M, Wang PS, Avorn J, Glynn RJ (2001) Performance of comorbidity scores to control for confounding in epidemiologic studies using claims data. Am J Epidemiol 154:854-864

28. Vanasse A, Dagenais P, Niyonsenga T, Gregoire JP, Courteau J, Hemiari A (2005) Bone mineral density measurement and osteoporosis treatment after a fragility fracture in older adults: regional variation and determinants of use in Quebec. BMC Musculoskelet Disord 6:33

29. Statistics Sweden. Area range of $\mathrm{H}$ regions (in Swedish). http:// www.scb.se/Grupp/Hitta_statistik/Regional\%20statistik/Kartor/ Dokument/H-region farg karta.pdf

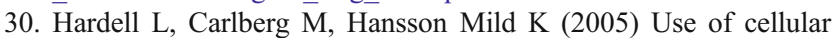
telephones and brain tumour risk in urban and rural areas. Occup Environ Med 62:390-394

31. Liel Y, Castel H, Bonneh DY (2003) Impact of subsidizing effective anti-osteoporosis drugs on compliance with management guidelines in patients following low-impact fractures. Osteoporos Int 14:490-495

32. Vik SA, Jantzi M, Poss J, Hirdes J, Hanley DA, Hogan DB, Maxwell CJ (2007) Factors associated with pharmacologic treatment of osteoporosis in an older home care population. J Gerontol A Biol Sci Med Sci 62:872-878

33. Lekkerkerker F, Kanis JA, Alsayed N, Bouvenot G, Burlet N, Cahall D, Chines A, Delmas P, Dreiser RL, Ethgen D, Hughes N, Kaufman JM, Korte S, Kreutz G, Laslop A, Mitlak B, Rabenda V, Rizzoli R, Santora A, Schimmer R, Tsouderos Y, Viethel P, Reginster JY (2007) Adherence to treatment of osteoporosis: a need for study. Osteoporos Int 18:1311-1317

34. Sambrook P, Cooper C (2006) Osteoporosis. Lancet 367:20102018

35. Johnell O, Jonsson B, Jonsson L, Black D (2003) Cost effectiveness of alendronate (fosamax) for the treatment of osteoporosis and prevention of fractures. Pharmacoeconomics 21:305-314

36. Zethraeus N, Borgstrom F, Strom O, Kanis JA, Jonsson B (2007) Cost-effectiveness of the treatment and prevention of osteoporosis - a review of the literature and a reference model. Osteoporos Int 18:9-23
37. Schousboe JT, Taylor BC, Fink HA, Kane RL, Cummings SR, Orwoll ES, Melton LJ 3rd, Bauer DC, Ensrud KE (2007) Costeffectiveness of bone densitometry followed by treatment of osteoporosis in older men. JAMA 298:629-637

38. McClung MR, Geusens P, Miller PD, Zippel H, Bensen WG, Roux C, Adami S, Fogelman I, Diamond T, Eastell R, Meunier PJ, Reginster JY (2001) Effect of risedronate on the risk of hip fracture in elderly women. Hip Intervention Program Study Group. N Engl J Med 344:333-340

39. Avenell A, Gillespie WJ, Gillespie LD, O'Connell DL (2005) Vitamin D and vitamin D analogues for preventing fractures associated with involutional and post-menopausal osteoporosis. Cochrane Database Syst Rev CD000227

40. Feldstein AC, Nichols G, Orwoll E, Elmer PJ, Smith DH, Herson M, Aickin M (2005) The near absence of osteoporosis treatment in older men with fractures. Osteoporos Int 16:953-962

41. Kiebzak GM, Beinart GA, Perser K, Ambrose CG, Siff SJ, Heggeness MH (2002) Undertreatment of osteoporosis in men with hip fracture. Arch Intern Med 162:2217-2222

42. Johnell O, Kanis J, Gullberg G (2001) Mortality, morbidity, and assessment of fracture risk in male osteoporosis. Calcif Tissue Int 69:182-184

43. Gruntmanis U (2007) Male osteoporosis: deadly, but ignored. Am J Med Sci 333:85-92

44. Chevalley T, Herrmann FR, Delmi M, Stern R, Hoffmeyer P, Rapin CH, Rizzoli R (2002) Evaluation of the age-adjusted incidence of hip fractures between urban and rural areas: the difference is not related to the prevalence of institutions for the elderly. Osteoporos Int 13:113-118

45. Larsson S, Eliasson P, Hansson LI (1989) Hip fractures in northern Sweden 1973-1984. A comparison of rural and urban populations. Acta Orthop Scand 60:567-571

46. Sanders KM, Nicholson GC, Ugoni AM, Seeman E, Pasco JA, Kotowicz MA (2002) Fracture rates lower in rural than urban communities: the Geelong Osteoporosis Study. J Epidemiol Community Health 56:466-470

47. Jonsson B, Gardsell P, Johnell O, Redlund-Johnell I, Sernbo I (1992) Differences in fracture pattern between an urban and a rural population: a comparative population-based study in southern Sweden. Osteoporos Int 2:269-273 